\title{
Sistemas integrados y gestión documental. La experiencia en Telecinco
}

\author{
Por Pilar-de Bustos-Pérez-de-Salcedo
}

\begin{abstract}
Resumen: La renovación tecnológica en la producción audiovisual, de la mano de la digitalización, asiste al reemplazo de la imagen analógica por ficheros de datos. El nuevo modelo de Telecinco está basado en acercar la tecnología al usuario, dar la máxima flexibilidad de acceso a la información, compartirla y crear un entorno personal donde la multifuncionalidad sea algo común. Se comparte la información sin necesidad de moverla.

Palabras Clave: Digitalización, Televisión, Archivos, Gestión documental, Centros de documentación, Flujos de trabajo, Sistemas integrados.

Title: Integrated systems and document management at Telecinco: a case study

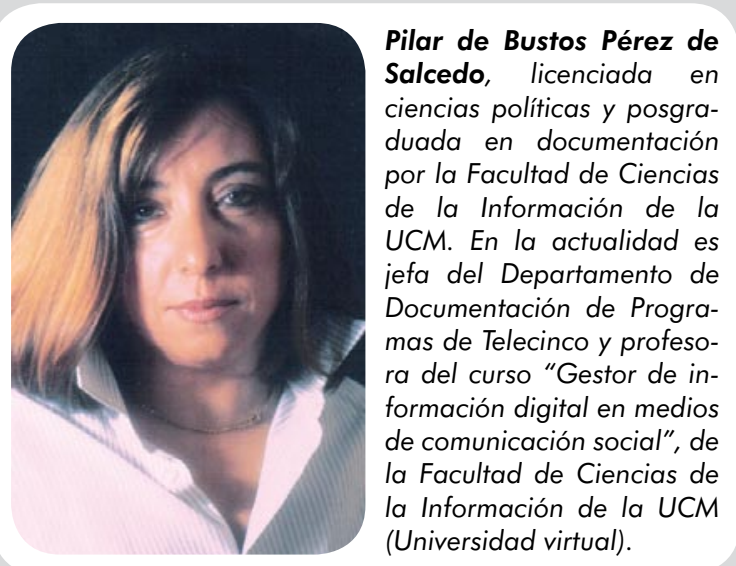

Abstract: Technological renewal in audio-visual production, thanks to digitalization, is replacing analog images with data files. The new model proposed by Telecinco (Spain's TV Channel 5) is based on bringing the technology closer to the user, providing maximum flexibility in information access and information sharing, and creating a multifunctional personal environment. Information is shared without moving it from TV5's repositories.
\end{abstract}

Keywords: Digitization, Television, Files, Document management, Documentation center, Workflow, Integrated systems.

Bustos-Pérez-de-Salcedo, Pilar-de. "Sistemas integrados y gestión documental. La experiencia en Telecinco". En: El profesional de la información, 2007, septiembre-octubre, v. 16, n. 5, pp. 450-455.

DOI: 10.3145/epi.2007.sep.07

\section{LA TRANSFORMACIÓN} TECNOLÓGICA en curso contempla la maquinaria de la televisión de forma global, integra diversos aspectos sustituyendo los anteriores métodos de trabajo $y$, con ellos, antiguas funciones $y$ competencias.

Se tiende a la convergencia de la televisión y el ordenador personal en una única plataforma, donde primen la interactividad y la capacidad de elección por parte del usuario entre una amplia oferta de contenidos.

Los sistemas utilizados en las diferentes áreas de actividad de una empresa de televisión están siendo sustituidos por componentes tecnológicos exclusivamente digitales. Este proceso afecta a todas las áreas neurálgicas: emisión, grabación, almacenamiento de imágenes y producción. En este contexto, los sistemas integrados de producción alcanzan la máxima potencialidad cuando incluyen herramientas destinadas a la gestión de archivos.

\section{"Los sistemas utilizados en las diferentes áreas de actividad de una empresa de televisión están siendo sustituidos por componentes tecnológicos exclusivamente digitales"}

\section{Del archivo analógico al archivo digital}

En el archivo analógico de la cadena de televisión Telecinco se ha conservado todo lo que se ha emitido desde marzo de 1990. En él se han llegado a tener almacenadas más de 400.000 cintas en formato
Betacam SP, 100.000 horas de emisión y más de 16.000 programas analizados y minutados, todo ello gestionado con el sistema documental BKM.

Sirva la foto de la figura 1 como recuerdo nostálgico de las extensas superficies de armarios compactados y ocupados por miles de cintas en unas condiciones especiales de temperatura y humedad, protegidas de la luz y de la contaminación ambiental y que día a día vemos desaparecer por otros espacios más reducidos y de mayor capacidad de almacenamiento. Además, se cuenta con la información en formatos más seguros para su conservación y las funciones de custodia, registro y préstamos se ven reemplazadas por transferencias de ficheros.

El archivo digital nació de una base de datos multimedia bajo $I n$ formix llamada Media 360 (Hydra) 


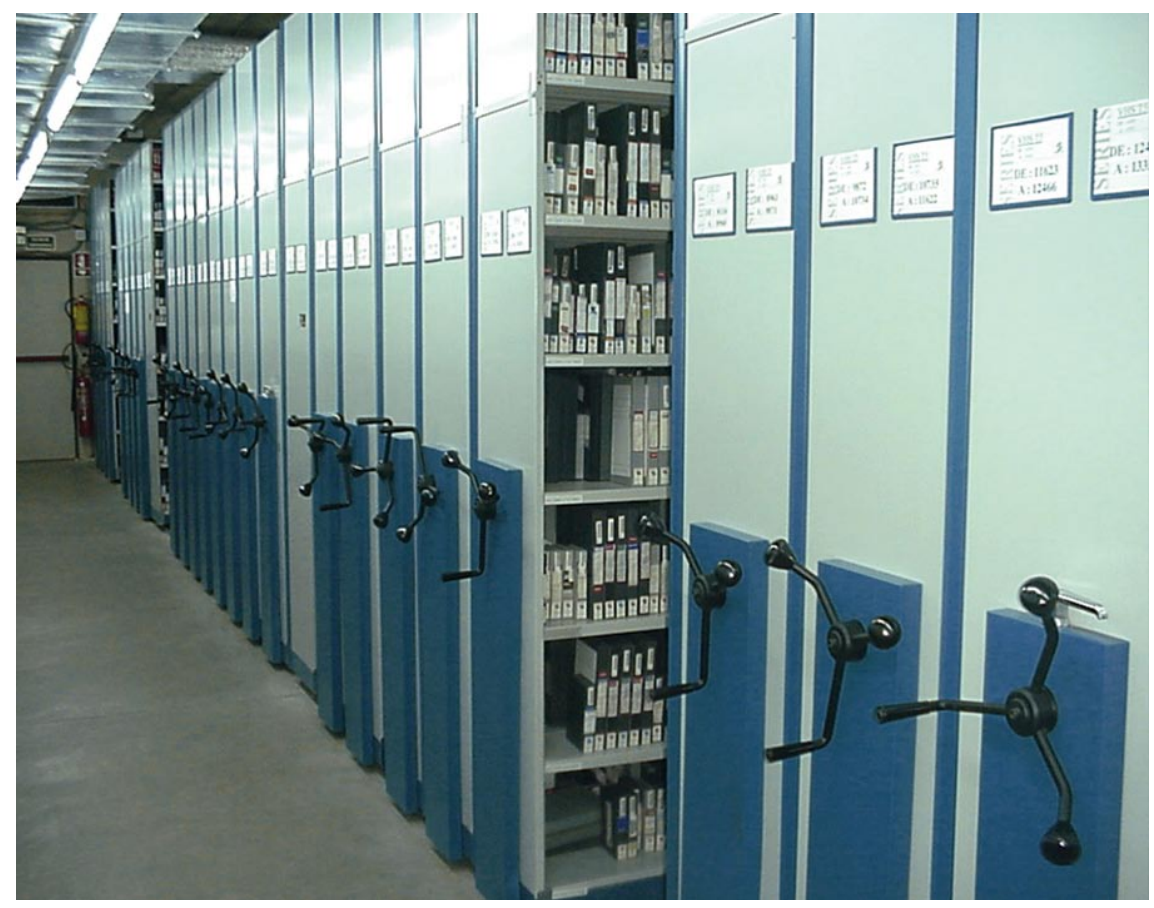

Figura 1

y desarrollada por Ascential. Se apoyaba en la catalogación de Virage y en la digitalización en baja calidad de Spectre View de Telemedia y servidores de alta calidad desarrollados en Telecinco.

Esta base de datos utilizaba herramientas propias como WebDataBase para su publicación vía web y Excalibur para la indexación de términos y su posterior búsqueda. La base de datos sigue siendo la misma en la actualidad (Media 360 modificada por Telecinco Aquarius) pero en vez de publicarse vía web se hace mediante aplicaciones desarrolladas en Telecinco que actúan como servidores de datos y clientes que se comunican con ellas a través de la red.

El archivo digital de la cadena está formado por:

- Un sistema de robots, con cintas Storagetek de datos.

- Catalogadores de vídeo, audio, OCR, reconocedores de voces y de caras.

- Servidores de vídeo (de alta y baja calidad).

- Una base de datos (Aquarius).
- Red de comunicaciones de alta velocidad.

Se tiene una capacidad para 18.000 cintas distribuidas en tres robots. Las primeras cintas que se utilizaron eran de $20 \mathrm{~GB}$, pero en la actualidad son de 200 y de 300 , con lo cual se ha multiplicado la capacidad del archivo ocupando el mismo espacio, pudiendo almacenar
360.000 horas en alta resolución. Actualmente hay 80.000 horas en millones de clips que pueden ser consultados y utilizados.

Los contenidos que pasan al archivo digital se graban en 3 niveles:

- Alta calidad 20Mbits/s Mpeg2 GOP (sistema group of pictures, o número de imágenes entre referencias keyframe).

- Baja calidad 1Mbits/s Mpeg 1: menor tamaño de almacenamiento y mayor rapidez de transporte por red.

- Keyframes (imágenes clave o de referencia) que se sacan de la señal SDI (serial digital interface es un sistema normalizado de transmisión de vídeo con una muy baja tasa de errores) y son fotografías de una imagen al detectar un movimiento, cambio de plano o variación. Sirven para la búsqueda de imágenes.

Diariamente se cargan en el archivo digital los siguientes contenidos:

- La copia judicial, que permite la visualización, navegación, descarga y análisis (asrunlog) de

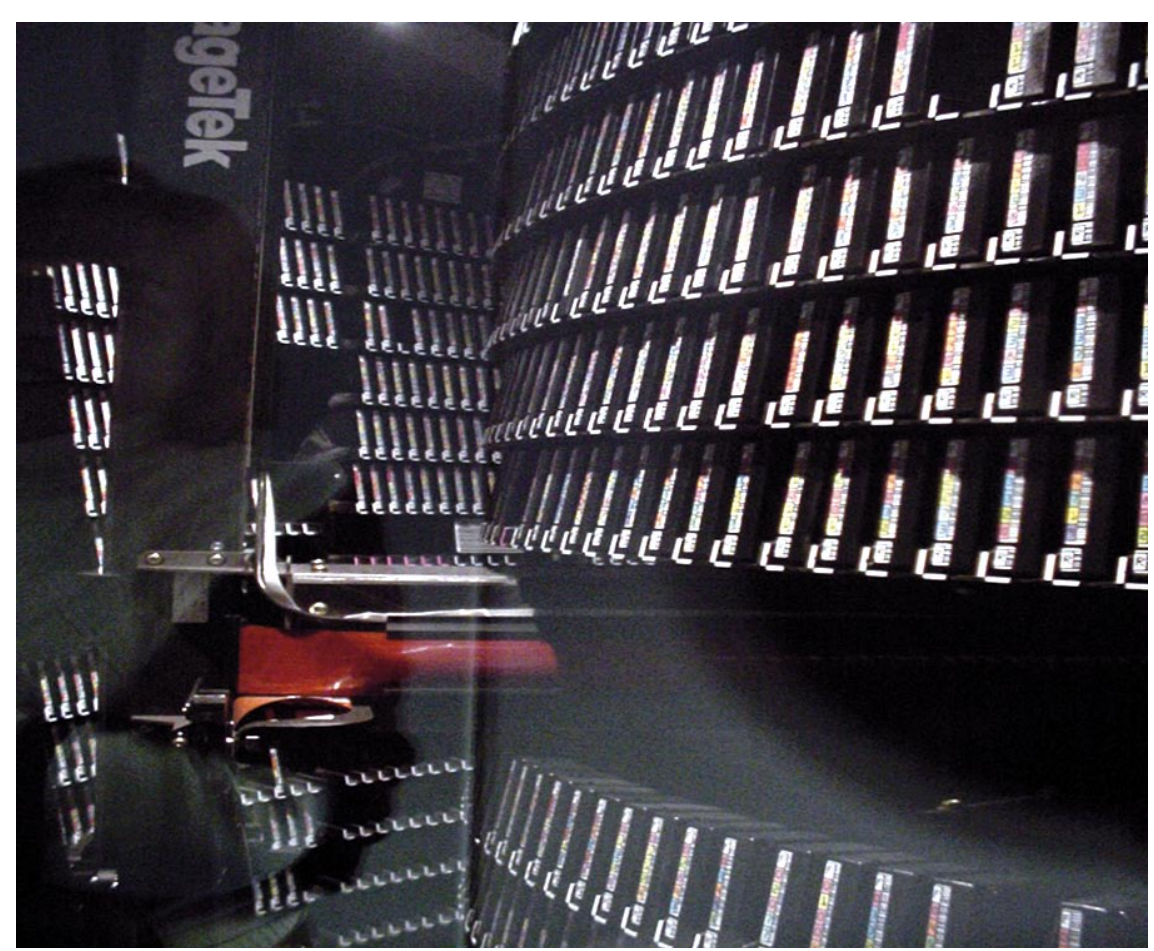

Figura 2 
cualquier día de la emisión de $T e$ lecinco.

- Los spots comerciales para su emisión.

- Piezas y brutos producidos por las redacciones de informativos y programas.

- Las emisiones de los informativos.

- Los programas en directo.

- Los programas históricos de la cadena, 112 horas/día. Téngase en cuenta que el archivo histórico se está haciendo en cinco puestos de ingesta durante 24 horas, a lo que hay que restar los cambio de turno y mantenimiento de los vídeos.

- Agencias nacionales e internacionales.

- La fonoteca (música comercial, efectos y música del grupo editorial de Telecinco).

- La conexión de las redacciones de los programas e informativos al propio archivo (consultas y peticiones de descarga a servidores).

La demanda multimedia de este fondo documental se puede dividir en peticiones de baja o de alta calidad.

a. Baja calidad, se realiza a través de dos canales únicos Aquarius, para la búsqueda de material y selección de segmentos y mediante la copia judicial.

b. Alta calidad, se produce a través de tres vías:

- Por medio de dos profiles (servidores de vídeo) conectados a la red de informativos.

- Con la ayuda de un sistema de almacenamiento de gran capacidad (SAN o storage area network, que es un conjunto de equipos de memoria en red) a las salas de edición no-lineal (ENL) conexionadas (hoy en día Incite). En el SAN se almacenan de manera intermedia clips para un posterior acceso rápi-

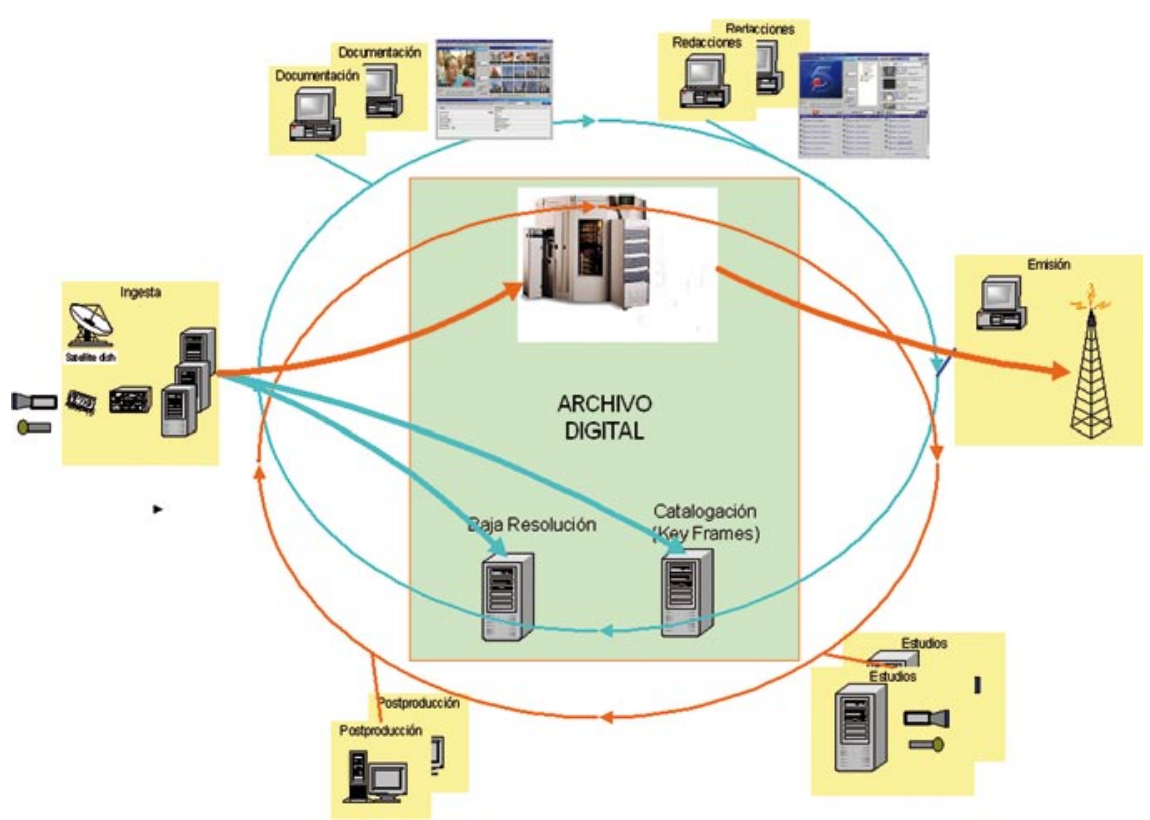

Figura 3 do y trabajos de edición / postproducción en desarrollo.

- Salas de volcado donde el usuario puede recoger el material solicitado.

La operación de volcado y recuperación de información corre a cargo de los distintos usuarios (técnicos del archivo, documentalistas $\mathrm{y}$ redactores).

Los usuarios demandan un determinado material a través de Aquarius y sus peticiones se transfieren automáticamente a la lista de demandas de los robots. Aquarius no es un gestor de base de datos como tal, pero sí se conecta con la base de datos del archivo (Informix) por medio de gateways o servidores de enlace que gestionan el enrutamiento de las consultas dependiendo del tráfico de cada uno de ellos. Una vez que el material se encuentra disponible en el servidor específico que se les ha asignado, les aparece en su terminal de Aquarius. El siguiente paso para los usuarios del área de programas es ir físicamente a la sala de volcado con sus cintas y descargarse la información.

El proceso en informativos es similar al descrito, con la salvedad de que cuando la información sale del archivo digital a sus servidores, ésta entra a su red de profiles y es visible en toda la redacción.

Los permisos de acceso a los contenidos del archivo es otro aspecto a considerar. Estos permisos, incluyendo a los usuarios de la copia judicial, los concede la Subdirección de Gestión Documental, que asigna a cada grupo de usuarios (redactores, documentalistas, realizadores, etc.) los diferentes contenidos (programas, informativos, agencias de noticias, etc.).

En cuanto a las condiciones de acceso, es previsible un incremento en la consulta y obtención directa por parte de los redactores y usuarios del material buscado, con 
el modelo de estaciones de trabajo sobre PC, en las que convergen funciones y operaciones que anteriormente se realizaban sobre equipos analógicos y por profesionales distintos.

\section{Digitalización del fondo histórico de Telecinco. Pasos del proceso}

La digitalización comenzó en noviembre de 2005 y cuando acabe 2007 habrán pasado a soporte digital 45.000 horas entre contenidos de programas (incluidos brutos) y 9.700 horas de informativos.

Lo primero ha sido seleccionar las cintas a digitalizar mediante un VTR y una aplicación desarrollada por el departamento de tecnología denominada Medialist, que se encarga de determinar los puntos de entrada y salida de las imágenes seleccionadas en cintas Betacam SP, así como de importar todos los datos de identificación de contenidos (título, fechas y minutados que ya existían con anterioridad en $B K M$, la base de datos documental de $B a$ ratz) y de generar un fichero que permite automatizar los servidores de grabación.

\section{"Cuando acabe 2007 habrán pasado a soporte digital 45.000 horas entre contenidos de programas y 9.700 horas de informativos"}

Posteriormente se reproducen, a partir del fichero de Medialist, las cintas de Betacam SP, generando cuatro ficheros de audio, uno de vídeo y otro con la extensión xml que durante los procesos de verificación se incluyen en el archivo digital y se almacenan en un servidor $S A N$ con capacidad de 5,7 TB. Se genera así la alta calidad y una réplica en

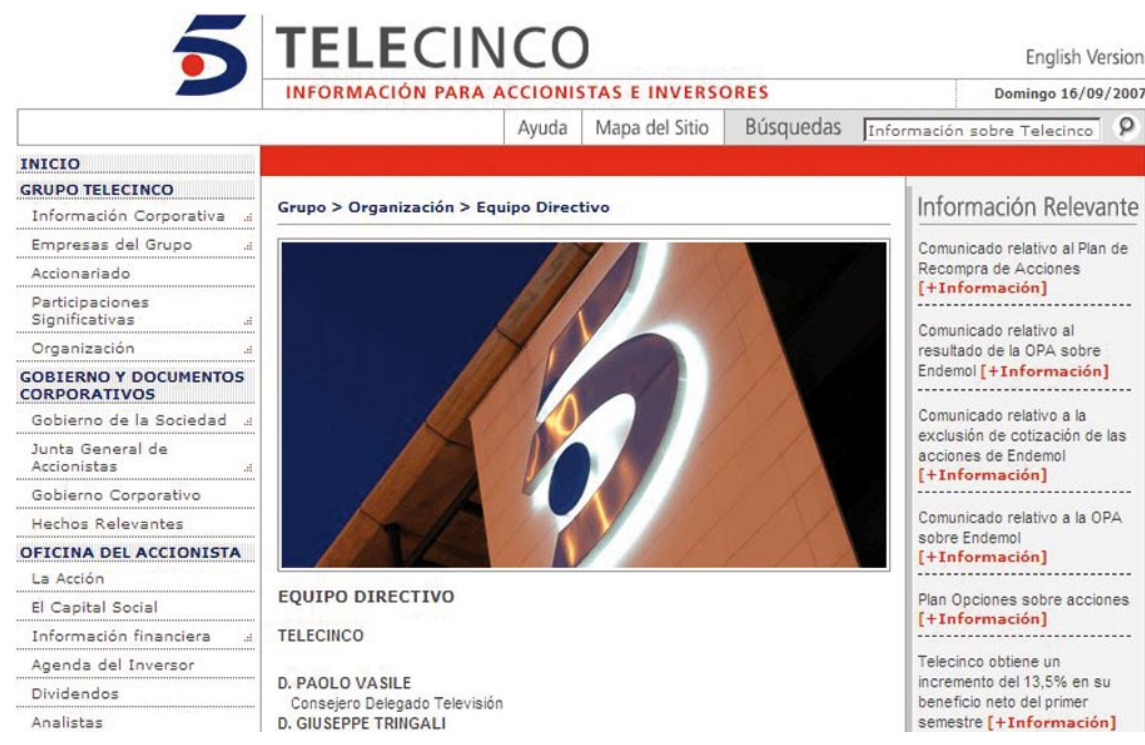

Figura 4

baja resolución y se crean pequeños fotogramas representativos (keyframes). Estos dos procesos se utilizan en la herramienta Aquarius para navegar por los vídeos y preseleccionar el material que posteriormente vamos a utilizar.

Un equipo se encarga de la verificación e ingesta de los ficheros en el archivo digital, utilizado para ello una aplicación concreta. El proceso termina en el Departamento de Documentación donde se procede al minutado de los programas que no estaban analizados y a la modificación del minutado migrado desde $B K M$. Por último, se añaden y actualizan los descriptores a cada segmento del vídeo.

\section{La recepción de imágenes vía internet. Las agencias}

Continuando con el avance de la digitalización en Telecinco, hay que destacar que desde hace más de un año se reciben las imágenes de agencias (Korpa, Europa, etc.) vía internet. Las cintas de vídeo trans- portadas por carretera han sido sustituidas por ficheros informáticos enviados a través de la Red.

Con anterioridad al actual sistema de recepción de imágenes, los coordinadores de las redacciones recibían por correo electrónico, a primera hora de la mañana, "la sabanilla" con los temas del día. Cada programa hacía su selección y más tarde se recibía la cinta de vídeo transportada en coche. Los redactores apenas disponían de tiempo (sobre todo los programas de la mañana) para poder visionarlas antes de empezar a editar sus piezas.

En la actualidad, las imágenes ya están disponibles en las redacciones por la mañana y los redactores pueden visualizar desde sus ordenadores y seleccionar segmentos para su posterior edición, a la vez que los documentalistas realizan el análisis documental de cada una de ellas. De esta forma se han conseguido reducir los tiempos de recepción y, sobre todo, la posibilidad de uso simultáneo de las imágenes.

\section{"Las cintas de vídeo transportadas por carretera han sido sustituidas por ficheros informáticos enviados a través de la Red"}


Las agencias son uno de los contenidos más demandados. Las imágenes se van recibiendo a lo largo de todo el día y, rápidamente, están disponibles en Aquarius para que los usuarios que consultan puedan realizar la selección y volcado del material audiovisual que necesitan, sin tener que recurrir al ya arcaico proceso del préstamo y visionado de una cinta de vídeo.

\section{La documentación}

Todos estos nuevos sistemas tecnológicos tendrán un impacto en la actividad documental. Tanto el proceso de gestión de imágenes por los documentalistas como las fórmulas de búsqueda y acceso a las mismas se verán afectados. Se facilitará el proceso de selección y agrupamiento de imágenes para su conservación y el tratamiento documental puede variar, adaptando la antigua necesidad de la descripción textual a la posibilidad de visualización inmediata.

Como consecuencia, la práctica de la documentación en televisión está experimentando una transformación que afecta a:

- Los sistemas de almacenamiento de imágenes digitalizadas que modifican el panorama actual dando mayor versatilidad en la disponibilidad de las mismas.

- Tratamiento documental, búsqueda y recuperación, junto a componentes clásicos como identificación de títulos, resúmenes o descriptores. Lo que caracteriza el análisis de materiales audiovisuales es la descripción de planos con lo que el documentalista relaciona las imágenes con un código de tiempo que señala su posición en la cinta. En la medida en que el interés de las imágenes es mayor, aumenta la necesidad de descripción, pero también permite:

- Posibilidad de trabajar con varios documentos a la vez.

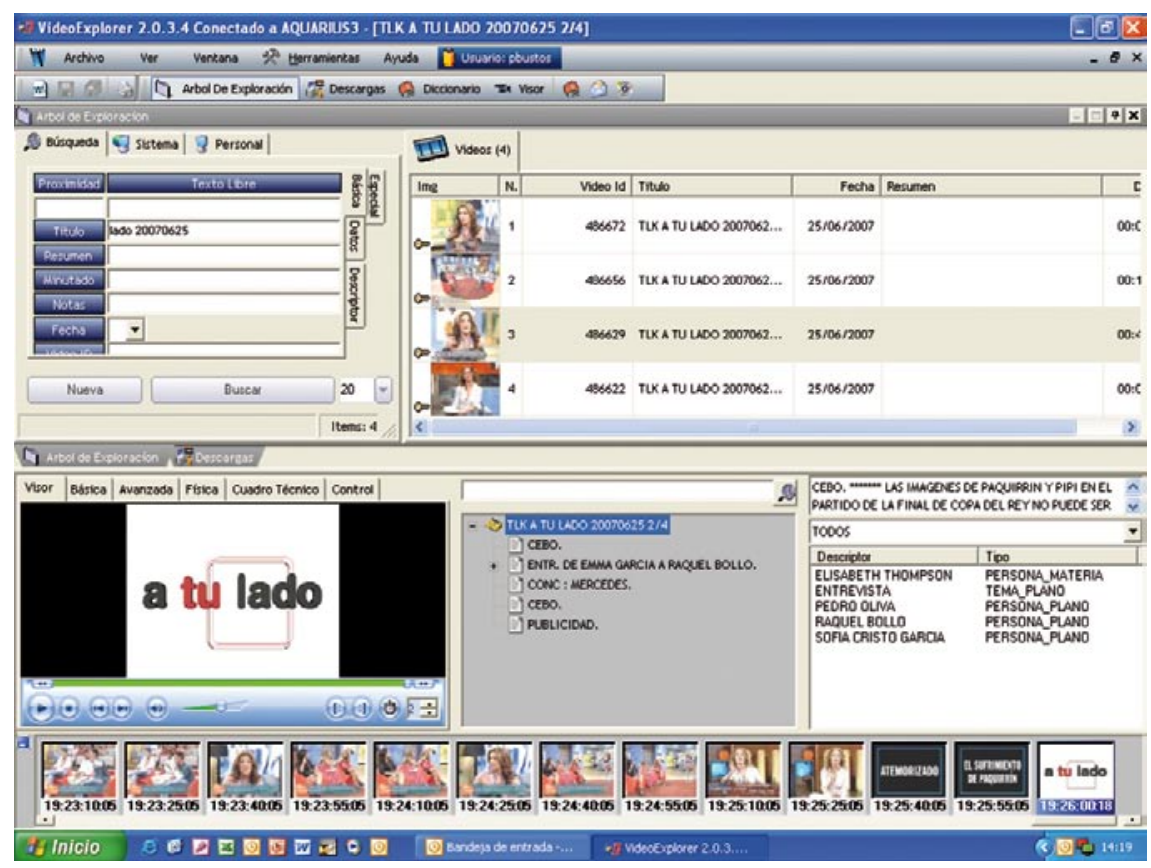

Figura 5
- Aparecen los descriptores a nivel de minutado.

- Tesauro facetado integrado en el archivo digital.

- Realización de búsquedas con operadores booleanos en los descriptores.

- Asociación de los keyframes más representativos del vídeo.

- Obtención e inserción de imágenes de vídeo.

- Gestión local en carpetas de lista, EDLs (edit decision lists) ${ }^{1} \mathrm{y}$ documentos.

- Estado de documentos abiertos para documentar a bloqueados.

- La nueva aplicación se ciñe a las normas establecidas dentro de la Ley Orgánica de Protección de Datos (LOPD).
- La fonoteca también está integrada en el archivo digital.

Los sistemas digitales pueden traer cambios que conllevarán la posibilidad de recuperar en la pantalla las imágenes buscadas. La clave está en qué volumen de imágenes puede ser accesible y con qué calidad, así como la posibilidad de contar con herramientas capaces de transferir automáticamente el audio a texto o la capacidad de identificar cambios de planos en una secuencia de vídeo, permitiendo extraer de cada uno de ellos uno o más cuadros (frames). Estos frames pueden incorporarse a una base de datos documental y servir como indicativos visuales, posibilitando en el siguiente nivel la catalogación automática de las imágenes.

\section{"Lo que caracteriza el análisis de materiales audiovisuales es la descripción de planos con lo que las imágenes se relacionan con un código de tiempo que señala su posición en la cinta"}


Parece posible que los rasgos identificativos de los rostros, las posiciones de los objetos, personas o colores podrán ser en un futuro cercano elementos de información utilizable en la identificación de una imagen y combinable en una búsqueda. Cuanto mayor es la información mayor es la necesidad de un equipo humano con conocimientos previos de cómo tratar, seleccionar y analizar la información para que esté disponible en el momento en que se vuelva a necesitar. En la información audiovisual televisiva, quizá todavía más que en otros, lo que no está documentado no existe.

Por último, sólo me queda señalar que el "milagro" de la digitalización en Telecinco es una realidad que se consolida día a día gracias al esfuerzo y la colaboración de todas las áreas implicadas en este proyecto: Documentación de Programas e Informativos, Archivo, Ingeniería Técnica, etc.

\section{Nota}

1. Una lista de decisión de edición (EDL) es una manera de representar una película o un vídeo que se está editando. Contiene una lista ordenada de los clips de un carrete o secuencia de imágenes, con temas y tiempos, tipos de transición entre escenas, que ya conforman el corte final definitivo.

Los EDLs se crean cuando se edita offline, o simplemente cuando la lista se hace a mano sobre papel. Actualmente la edición lineal han sido sustituida por la no-lineal (ENL), con sistemas que pueden producir EDLs que se conforman automáticamente en un sistema online de edición.

Algunos formatos, tal como CMX3600, pueden representar sólo decisiones de edición sencillas. Tanto XML como Advanced authoring format son formatos avanzados que pueden contener EDLs sofisticados.

http://en.wikipedia.org/wiki/Edit_decision_list

\section{Bibliografía}

Arratia, Amira. "Archivos audiovisuales latinoamericanos: visión de futuro". En: Cuadernos de documentación multimedia, 2002, n. 13.

http://multidoc.rediris.es/cuadernos/num13/ponencias/viernes/01sesion_pdf/AmiraArratia.pdf

Edmondson, Ray. Filosofía y principios de los archivos audiovisuales. Paris, 2004.

Gouyet, Jean-Noël; Gourdon, Anne; Ber- trand, Frédéric. Systèmes de compression-Sons. Images fixes. Images vidéo. Les études de la recherche. INA, Bry sur Marne, 1998.

Harrison, Helen (ed.). Audiovisual archives: a practical reader (CII.97/WS/4). París: Unesco, 1997.

López-Yepes, Alfonso. Documentación audiovisual y multimedia, medios de comunicación y televisión educativa iberoamericana. Tele-seminario ATEI/Universidad Complutense de Madrid. Cd-rom, Servicio de Documentación Multimedia, Madrid, 2000

Rodríguez-Bravo, Blanca. «El documento audiovisual en las emisoras de televisión: selección, conservación y tratamiento». En: Biblos, 2004, diciembre, v. 5, n. 20, pp. 29-39.

Tufte, Edward. Visual explanations: images and quantities, evidence and narrative. Cheshire: Graphics Press, 2002.

Unesco: Recomendación sobre la salvaguardia y la conservación de las imágenes en movimiento de la UNESCO. Aprobada por la Conferencia General en su $21^{\text {a }}$ reunión, Belgrado, 27 de octubre de 1980

Pilar-de Bustos-Pérez-de-Salcedo, Departamento de Documentación de Programas de Telecinco.

pbustos@telecinco.es

\section{Máster Oficial Universitario}

\section{Contenidos y Aspectos Legales en la Sociedad de la Información}

\section{Objetivos}

Especializar a profesionales de la información en la gestión de contenidos a través de diferentes plataformas para todos los ámbitos de la sociedad. Ahondar y ampliar los conocimientos en Archivistica, Biblioteconomía y Documentación con un enfoque dirigido a la aplicación de las tecnologías de la información en sus nuevos canales.

\section{Especialidades}

- Información y Documentación: Gestión de contenidos multicanal.

- Gestión de Archivos y e-administración.

- E-Consulting en la sociedad de la información

Estructura del Máster

75 ECTS a impartir en un curso académico. Horario de Tarde.

Materias - 45 ECTS - que estudian las técnicas aplicadas a la gestión de contenidos en diversos formatos y distribuidos por canales como Internet, móviles.
Temas centrales son los contenidos audiovisuales, la digitalización de todo tipo de soportes o la importancia de los archivos: su gestión, puesta en valor y la reutilización de la información.

\section{Asignaturas de libre configuración curricular:} 12 ECTS

Proyecto fin de Máster:

15 ECTS

Profesorado

Este Máster será impartido por profesorado de diversas Universidades Nacionales asi como profesionales de reconocido prestigio.

\section{Fechas}

Plazos de preinscripción:

Del 4 al 21 de Septiembre de 2007

Inscripción :

Del 1 al 15 de Octubre de 2007

\section{Información}

Secretaría del Departamento de Comunicación Audiovisual, Documentación e Historia del Arte (DCADHA) de la UPV.

Teléfono: 963877390

e-mail: dephar@upvnet.upv.es

Página Web:

www.upv.es/postgradooficial/central_master.htm

\section{Preinscripción}

unw.upv.es/postgradooficial/central_admision.htm

\section{Acceso a programa de Doctorado}

